\title{
Association of serum asymmetric dimethyl-arginine and troponin I levels as a risk of myocardial infarction in thalassemia
}

\author{
Nawal Helmi ${ }^{1}$, Hani Choudhry ${ }^{1,2}$, Qari $\mathrm{M}^{3}$, Taha A Kumosani ${ }^{1,2,4,5}$, Abdulrahman L AL-Malki ${ }^{1,2,6}$, \\ Said Salama Moselhy ${ }^{1,4,6,7}$, Afnan T Kumosani ${ }^{8}$
}

1. Biochemistry Department, Faculty of science, King Abdulaziz University (KAU), Jeddah, Kingdom of Saudi Arabia.

2. Cancer Metabolism and Epigenetic Unit, Faculty of Science (KAU) ; Cancer and Mutagenesis Unit, King Fahd Medical Research Center (KAU).

3. Hematology department, Faculty of medical science, King Abdulaziz University, Saudi Arabia.

4. Experimental biochemistry unit, King Fahd Medical Research center, KAU.

5. Production of bio products for industrial applications research Group, KAU.

6. Bioactive Natural Products Research Group, KAU.

7. Biochemistry department, Faculty of science, Ain Shams University, Cairo, Egypt.

8. Department of pathology and Laboratory Medicine, Blood Bank Transfusion medicine, King Abdulaziz Medical City, Jeddah, National Guards, , Jeddah, 21423.

\begin{abstract}
Background: The current study evaluated level of serum asymmetric dimethylarginine (ADMA) and its association to cardiac biomarkers in thalassemia patients for early diagnosis of abnormality in myocardial infarction.

Subjects and methods: This study was conducted on 80 subjects divided into four groups each with 20 subjects. Group I: Control: healthy subjects. Group II: Myocardial infarction: Patients with elevated serum troponin T. Group III: thalassemia patients. Group IV: thalassemia with myocardial infarction patients: Included 20 thalassemia patients with Myocardial infarction. Serum samples were subjected for assay of creatine kinase (CK:MB), Lactate dehydrogenase, troponin I,ADMA, Serum MDA level was determined.

Results: Data obtained showed that serum CKMB, LDH1, AST, Troponin T and ADMA levels were significant elevated in MI with or without Thalassemia compared with control groups. Serum MDA was statistically significantly elevated in MI with or without Thalassemia compared with control groups. The serum level of troponin $\mathrm{T}$ showed an area under curve (AUC) of 0.92 , (sensitivity $91.0 \%$ and specificity, 88\%). Also, the ADMA supported the diagnostic profile, showing an AUC of 0.85 with (sensitivity, 92.0\%; specificity, 91,9\%).

Conclusion: Serum ADMA is sensitive marker for incidence of MI in thalassemia patients.

Keywords: CKMB, LDH1, AST, Troponin T, asymmetric dimethylarginie, Thalassemia.

DOI: https://dx.doi.org/10.4314/ahs.v18i3.30

Cite as: Helmi N, Choudhry H, Qari M, Kumosani TA, AL-Malki AL, Moselhy SS, Kumosani AT. Association of serum asymmetric dimethyl-arginine and troponin I levels as a risk of myocardial infarction in thalassemia. Afri Health Sci. 2018;18(3): 720-726. bttps://dx.doi. org/10.4314/abs.v18i3.30
\end{abstract}

\section{Corresponding author:}

Abdulrahman L AL- Malki,

Biochemistry Department,

Faculty of science,

King Abdulaziz University (KAU),

Jeddah, Kingdom of Saudi Arabia.

Email:smbala22@hotmail.com

\section{Introduction}

Thalassemias are known genetically inherited blood disorders, that can result in abnormal hemoglobin formation. Quite often, the individuals suffer from mild to severe anemia, yellowish skin, enlarged spleen, dark urine, bone problems and slow growth (among children) ${ }^{1}$. Mainly, there are two types of thalassemias, the alpha thalassemia and the beta thalassemia; their severity is dependent upon

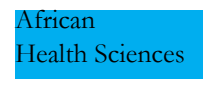

(C) 2018 Helmi et al. Licensee African Health Sciences. This is an Open Access article distributed under the terms of the Creative commons Attribution License (https://creativecommons.org/licenses/BY/4.0), which permits unrestricted use, distribution, and reproduction in any medium, provided the original work is properly cited. 
the number of missing genes out of four for alpha globin and two for beta globin ${ }^{1}$. In alpha thalassemia, genes HBA1 and HBA2 (on chromosome 16) are involved, of which, two gene loci are present, and therefore, four alleles exist.As a result of alpha thalassemia, there is a decrease in the alpha-globin production, hence alpha-globin chains production is lowered, which in turn results in an excess of beta chains among the adults and gamma chains in newborns. This excess of beta chains produce tetramers which are unstable (known as hemoglobin $\mathrm{H}$ or $\mathrm{HbH}$ of 4 beta chains), and show defective oxygen release. In beta thalassemia there are mutations in the HBB gene (on chromosome 11), and the severity depends on the nature and on the presence of mutations in one or both alleles. The clinical picture is described by the situation of both the alleles: $\beta$ thalassemia major: caused by a $\beta 0 / \beta 0$ genotype, i.e., no functional $\beta$ chains are formed, most severe form of $\beta$-thalassemia. $B$ thalassemia minor: caused by $\beta / \beta 0$ or $\beta / \beta+$ genotypes. Here, mutation is present in one of the two $\beta$ globin alleles, therefore, the production of $\beta$ chain is not compromised.

Anemia and chronic ineffective erythropoiesis are the characteristics of thalassemia major as its primary problems, so, certain physiological adaptations are produced in the cardiovascular system. People with chronic anemia have an increased cardiac output, so that the oxygen delivery is maintained. This results in increased heart rate and cardiac dimensions. Patients with chronic anemia have higher resting oxygen consumption and lower reserves. With increased resting metabolism, there is also an increase in oxidative stress.Hypersplenism is also found to be common among the people suffering from thalassemia. This condition may require and necessitate the removal of spleen. In the removal of hematologic debris from cardiovascular system, spleen nevertheless has a critical function. Platelet fragments, RBC fragments, phosphatidylserine positive platelets are known strong pro-coagulants. Moreover, they inhibit nitric oxide (a powerful vasodilator) and stimulate substances that promote vasoconstriction, like: endothelin and prostaglandins, and produce endothelial proliferation ${ }^{2}$. This implies that splenectomy (removal of spleen), may carry a strong risk of intra vascular thrombosis. Individuals suffering from thalassemia acquire excess of iron because of an increase in absorption of iron and transfusion therapy. Iron is known to be toxic to endocrine glands supporting the heart. Iron may poison thyroid and parathyroid glands, thereby affecting metabolism and calcium regulation.

Asymmetric dimethylarginine (ADMA) is a modified amino acid that occurs naturally in human blood, and is known to inhibit nitric oxide production. Nitric oxide plays a key role in vascular tone regulation, thereby has an important contribution in atherosclerosis ${ }^{3,4,5}$. Studies suggested that higher the values of circulating ADMA level more are incidences of cardiovascular disease (CVD). Studies carried out in mice with elevated ADMA levels (genetically and chemically) exhibited an increase in blood pressure and systemic vascular resistance $e^{6,7}$, on the other hand they showed a decrease in these parameters with low ADMA level ${ }^{8}$. In addition to this, high ADMA and low NO may result in vascular inflammation ${ }^{9}$, LDL oxidation $^{10}$ endothelial cell apoptosis ${ }^{11}$ aggregation and adhesion of platelets ${ }^{12}$. Thus, it could be said that ADMA and NO play a crucial role in endothelial dysfunction, which is the first step in atherogenesis, and hence ADMA may also be a risk factor for cardiovascular disease in thalassemia, in a way by inhibition of nitric oxide. Troponin is a complex protein (consisting of three proteins: troponin $\mathrm{C}$, troponin I, and troponin T). Troponin is important in muscle contraction, both in skeletal and cardiac muscles. Troponin I holds actin-tropomyosin complex in place by binding to actin in thin myofilaments, due to which, in a relaxed muscle, myosin cannot bind with actin (letter I stands for inhibitory character). Troponin I is useful in laboratory diagnosis of heart attack.

Due to iron overload, the first cause of death among thalassemia major patients is iron induced cardiac dysfunction (abnormality of pumping and conduction) ${ }^{13,14,15}$. It was reported that high ferritin (iron containing protein in blood) concentration is related to high troponin levels in patients who are receiving high iron sucrose ${ }^{16}$. Iron absorption is enhanced by mutations in the hypophis-hypothalamus axis in JAK STAT pathway ${ }^{17}$. Iron is reportedly deposited in the patients in parenchyma tissues, including the heart. This increase in iron levels results in free radical formation and lipid oxidation of cardio-myocyte membranes, eventually leading to damage ${ }^{18}$. During cell damage, there is a loss of myocyte contraction force resulting in the release of troponin. Increase in troponin levels 
can be considered a specific and a sensible biomarker for myocardial injury in the early stages and could be well referred as the beginning of a microinfarct ${ }^{19}$.

Additional experiments were performed by Yu Han et $\mathrm{al}^{20}$ in which using human umbilical vein endothelial cells (HUVECs) it was shown that the detrimental effect of troponin I (cardiac troponin I)was related to increase in VCAM 1expression (functions as a cell adhesion molecule) induced by troponin I, and adhesion of human monocytes THP-1 (a human monocytic cell line derived from an acute monocytic leukemia patient) mediated by VCAM 1 to HUVECs, which could be neutralized by VCAM1 antibody. It was reported that NF-kB and tolllike receptor 4 (TLR4), both had a role involved this signaling pathway. This was inferred due to the fact that troponin I's effect on VCAM 1 expression and adhesion of monocytes to the endothelial cells was inhibited if there was any blockade of either of the two - TLR4 or NF$\mathrm{kB}$. Furthermore, troponin I augmented cardiac injury in rats with myocardial ischemia- reperfusion injury was reduced after the inhibition of TLR $4^{20}$. They concluded that troponin I aggravates myocardial ischemia- reperfusion injury by induction adhesion of monocytes to vascular endothelial cells by activating TLR4/NF-kB pathway. Thus, inhibiting of TLR4 may prove to be an alternative strategy to reduce troponin I induced myocardial inju$r \mathrm{y}^{20}$.The rationale of this study was to evaluate serum dimethylarginine and its association to cardiac biomarkers in thalassemia patients for early diagnosis of myocardial infarction to avoid its complications.

\section{Subjects and methods}

Informed consent was taken from all individuals included in this study. The study was done according to ethical committee of King Abdulaziz University. This study was conducted on 80 subjects admitted to the Hematology Department, King Abdulaziz University. All individual were subjected to full clinical examination (diabetes, hypertension, cardiovascular disorder). They were classified according to clinical examination to the following groups: Group I: Control group: Included 20 healthy subjects with no evidence for any symptoms of clinical disorder. Group II: Myocardial infarction patients: Included 20 patients all patients of this group were confirmed to have myocardial infarction by clinical examination and elevated serum troponine T. Group III: Thalassemia patients: Included 20 patients who were graded according to blood picture, all patients of this group were confirmed to have thalassemia by clinical examination and hematological parameters. Group IV: Thalassemia with myocardial infarction: Included 20 thalassemia patients with myocardial infarction, all patients of this group were confirmed by clinical examination and hematological parameters. Exclusion criteria included, liver disease, renal dysfunction, hyperplasia and diabetes.

\section{Sample collection}

A five $\mathrm{ml}$ blood sample was collected from each subject. Serum was separated by centrifugation at 4000 r.p.m for 10 minutes. Serum was stored at $-80^{\circ} \mathrm{C}$ until used.Serum samples were subjected to the following examination. Creatine kinase (CK2:MB), Lactate dehydrogenase (LDH1), Serum Aspartate transaminase, Serum troponin I, by kits from BioLab, Jeddah.

\section{Assay of asymmetric dimethylarginine (ADMA).}

Serum ADMA was measured by HPLC ${ }^{15}$. N-monomethyl L-arginine (NMMA) was used as the internal standard . Serum ADMA was extracted by $(\mathrm{NH} 3 / 1 \mathrm{M} \mathrm{NaOH} /$ waterCH3OH) $(10 / 0.5 / 40 / 50 ; \mathrm{v} / \mathrm{v} / \mathrm{v} / \mathrm{v})$. The it was derivatized with ortho-phthaldialdehyde (OPA) reagent $(1: 1 ; \mathrm{v}: \mathrm{v})$ and injected into the HPLC system, with a fluorescent detector. Chromatographic separation was performed isocratically at $100 \%$ mobile phase A, with $25 \mathrm{mmol} / \mathrm{L}$ phosphate buffer ( $\mathrm{pH}$ 6.8) containing 6.5\% $\mathrm{CH} 3 \mathrm{CN}$, at a flow rate of $1.1 \mathrm{~mL} / \mathrm{min}$. Mobile phase was water: $\mathrm{CH} 3 \mathrm{CN}(50: 50, \mathrm{v}: \mathrm{v})$, and the flow rate was increased to $2.0 \mathrm{~mL} / \mathrm{min}$.

\section{Statistical analysis}

Statistical analysis will be done by SPSS using student's t-test. Value of $\mathrm{P}<0.05$ was considered as statistically significant. ANOVA test was performed to correlate between different groups.

\section{Results}

Table (1) showed that serum CKMB, LDH1, AST, Troponin $\mathrm{T}$ and ADMA levels were significantly elevated in MI with or without Thalassemia compared with control groups $(p<0.001)$ for each. Serum malondialdhyde was statistically significantly elevated in MI with or without Thalassemia compared with control groups $(\mathrm{p}<0.001)$. ANOVA analysis showed non-significant changes observed between MI and MI with Thalassemia. Non-sig- 
nificant changes in the levels of hemoglobin in MI compared with control but it was significantly reduced in thalassemia with or without MI. Serum MDA was significantly increased in MI with or without Thalassemia $(\mathrm{P}<0.001, \mathrm{p}<0.001)$. The level of serum ADMA lev- el was positively correlated with increase in troponin $\mathrm{T}$ $(\mathrm{P}<0.01)$. The cut-off value in $90 \%$ patients at the MI with or without Thalassemia $70 \%$. Positive correlations were observed between troponin $(\mathrm{r}=0.66)$, and ADMA $(\mathrm{r}=0.73)$ while there was no correlation with other laboratory markers such as plasma AST and LDH.

Table (1). The levels of hemoglobin, activities of serum CK;MB, $\mathrm{LDH}_{1}$ and AST in All studied groups (mean \pm SD).

\begin{tabular}{|c|c|c|c|c|}
\hline Patients Groups & \multirow{2}{*}{$\begin{array}{c}\text { Control } \\
n=20\end{array}$} & \multirow[t]{2}{*}{$\begin{array}{c}\text { MI } \\
n=20\end{array}$} & \multirow[t]{2}{*}{$\begin{array}{c}\text { Thalass. } \\
\mathrm{n}=20\end{array}$} & \multirow[t]{2}{*}{$\begin{array}{c}\text { MI + Thalass. } \\
n=20\end{array}$} \\
\hline Parameters & & & & \\
\hline \multicolumn{5}{|l|}{$\begin{array}{c}\text { Hemoglobin } \\
(\mathrm{g} / \mathrm{dl})\end{array}$} \\
\hline $\mathrm{Mean}+\mathrm{SD}$ & $15.3 \pm 2.1$ & $14.3 \pm 2.4$ & $9.5 \pm 1.2$ & $10.1 \pm 1.1$ \\
\hline$P_{1}$ value & --- & $<0.001$ & $\begin{array}{l}<0.001 \\
<0.001\end{array}$ & $\begin{array}{l}<0.001 \\
<0.05\end{array}$ \\
\hline$P_{2}$ value & --- & --- & & \\
\hline \multicolumn{5}{|l|}{$\begin{array}{c}\text { CK:MB } \\
(\mathrm{U} / \mathrm{L})\end{array}$} \\
\hline $\mathrm{Mean} \pm \mathrm{SD}$ & $33.8 \pm 4.02$ & $67.5 \pm 5.06$ & $31.1 \pm 3.2$ & $50.3 \pm 5.18$ \\
\hline$P_{l}$ value & --- & $<0.001$ & $\begin{array}{l}<0.001 \\
<001\end{array}$ & $<0.001$ \\
\hline$P_{2}$ value & --- & --- & & \\
\hline \multirow{2}{*}{\multicolumn{5}{|c|}{$\begin{array}{l}\mathrm{LDH}_{1} \\
(\mathrm{U} / \mathrm{L})\end{array}$}} \\
\hline & & & & \\
\hline Mean $\_$SD & $62 \pm 4.5$ & $84 \pm 8.7$ & $55 \pm 5.8$ & $90 . \pm 9.9$ \\
\hline$P_{1}$ value & --- & $<0.05$ & N.S & $<0.001$ \\
\hline$P_{2}$ value & --- & --- & --- & \\
\hline \multicolumn{5}{|l|}{ AST } \\
\hline$(\mathrm{U} / \mathrm{L})$ & & & & \\
\hline Mean \pm SD & $22 \pm 2.02$ & $81 \pm 9.12$ & $32 \pm 3$ & $65 \pm 4$ \\
\hline$P_{l}$ value & --- & $\begin{array}{l}<0.001 \\
<0.001\end{array}$ & N.S & $\begin{array}{l}<0.001 \\
<0.001\end{array}$ \\
\hline$P_{2}$ value & --- & & --- & \\
\hline
\end{tabular}

$\mathrm{n}=$ number of cases $p_{I}$ value, thalassemia, Myocardial infarction and thalassemia with Myocardial infarction versus control. $\quad p_{2}$ value, thalassemia with Myocardial infarction versus Myocardial infarction 
Table (2). The levels of serum troponin T, ADMA and MDA in all studied groups (mean \pm SD)

\begin{tabular}{|c|c|c|c|c|}
\hline Patients Groups & \multirow{2}{*}{$\begin{array}{c}\text { control } \\
\mathrm{n}=20\end{array}$} & \multirow{2}{*}{$\begin{array}{c}\text { MI } \\
n=20\end{array}$} & \multirow{2}{*}{$\begin{array}{c}\text { Thalass. } \\
n=20\end{array}$} & \multirow{2}{*}{$\begin{array}{c}\text { MI + Thalass } \\
n=20\end{array}$} \\
\hline Parameters & & & & \\
\hline \multicolumn{5}{|l|}{$\begin{array}{c}\text { Troponin } \mathrm{T} \\
\text { (ug/l) }\end{array}$} \\
\hline Mean+SD & $71 \pm 10.2$ & $140 \pm 15.3$ & $61 \pm 6.8$ & $110 \pm 13.2$ \\
\hline$P_{l}$ value & --- & $<0.001$ & $\begin{array}{l}<0.001 \\
<0001\end{array}$ & $<0.001$ \\
\hline$P_{2}$ value & --- & --- & & \\
\hline \multicolumn{5}{|l|}{$\begin{array}{l}\text { ADMA } \\
(\mathrm{ug} / 1)\end{array}$} \\
\hline $\mathrm{Mean} \pm \mathrm{SD}$ & $3.5 \pm 0.8$ & $23.2 \pm 1.1$ & $9.7 \pm 2.8$ & $18.3 \pm 3.2$ \\
\hline$P_{1}$ value & --- & N.S & $\begin{array}{l}<0.001 \\
<0001\end{array}$ & $<0.01$ \\
\hline$P_{2}$ value & --- & --- & & $<0.001$ \\
\hline \multicolumn{5}{|l|}{$\begin{array}{c}\text { MDA } \\
\text { (umole/l) }\end{array}$} \\
\hline Mean + SD & $16 \pm 2.5$ & $33.9 \pm 4.07$ & $31 \pm 4.07$ & $43 \pm 5.2$ \\
\hline$P_{1}$ value & & $<0.001$ & $<0.001$ & $<0.001$ \\
\hline$P_{2}$ value & --- & $<0.001$ & $<0.001$ & $<0.01$ \\
\hline & --- & & & \\
\hline
\end{tabular}

$\mathrm{n}=$ number of cases $p_{1}$ value, thalassemia, Myocardial infarction and thalassemia with Myocardial infarction versus control. $p_{2}$ value, thalassemia with Myocardial infarction versus Myocardial infarction

Table 3. Receiver operating curve (ROC) analysis of investigated urine parameters asa test for diagnosis of diabetic nephropathy

\begin{tabular}{lccr} 
Variable & ADMA & TropT & CK:MB \\
AUC & 0.91 & 0.78 & 0.95 \\
Sensitivity (\%) & $89 \%$ & $92.3 \%$ & $95.5 \%$ \\
\hline Specificity (\%) & $90.4 \%$ & $89.9 \%$ & $97 \%$
\end{tabular}

AUC; area under curve Receiver operating curve (ROC) analysis were performed to define the diagnostic profile markers among subjects with MI. The serum level of troponin T showed an area under curve (AUC) of 0.92 with (sensitivity $91.0 \%$ and specificity, 88\%). Also, the ADMA supported the diagnostic profile, showing an AUC of 0.85 with (sensitivity, $92.0 \%$; specificity, $91,9 \%$ ).

\section{Discussion}

Contributing to the correct orientation in the therapeutic protocol in management of early myocardial infarction in thalassemia subjects to avoid complications of chronic cardiac dysfunctions, we designed a prospective study to assess the association between plasma ADMA level and incidence of MI in patients with thalessemia.

Data obtained showed that, serum troponin T was significantly elevated in pateints with MI and thalassemia cases, but In MI it was higher statistically $(\mathrm{p}<0.001)$. This is in- 
dicated that, troponin $\mathrm{T}$ was released from muscle heart as a result of heart injury. This is was more sensitive test than myoglobin ${ }^{12}$.

It was found that in this study, serum ADMA was significantly elevated in MI and thalassemia and MI with thalassemia patents compared with control group $(\mathrm{p}<0.01$, 0.001 and 0.01 ) respectively. Serum ADMA is a well-characterized circulating endogenous inhibitor of NO synthase $^{6,7}$, and may compete with L-arginine as the substrate for NO synthase which can lead to decreases in both the production and availability of endothelium-derived $\mathrm{NO}^{8}$. Elevated plasma ADMA level has been associated with $\mathrm{MI}^{7,9}$ and was observed in patients with various risk factors for atherosclerosis ${ }^{10,11}$. Several studies have shown that plasma ADMA level may predict the progression of renal injury in patients with early-stage $\mathrm{MI}^{15,16}$.

Since NO normally inhibits platelet aggregation and adhesion ${ }^{14,16}$, any decrease in NO levels may trigger thrombus formation and development on a ruptured plaque. It is documented that NO generated from activated platelets inhibits further platelet recruitment to the developing thrombus ${ }^{17}$. This is recommended by elevation of cardiac markers CKMB and LDH1 and troponin $\mathrm{T}^{25}$.

High ADMA levels are also associated with elevated cardiac output ${ }^{30}$, mechanisms that may well be incriminated in the morning occurrence of myocardial infarction ${ }^{6-11}$.

However, previous studies that investigated the troponin in MI found that it was correlated with ADMA level ${ }^{33}$.

It was stated that, ADMA was elevated in MI with or without thalassemia but the elevation in thalassemia was higher than without.

AUC; area under curve Receiver operating curve (ROC) analysis was performed to define the diagnostic profile markers among subjects with MI. The serum level of troponin $\mathrm{T}$ showed an area under curve (AUC) of 0.92 with (sensitivity $91.0 \%$ and specificity, 88\%). Also, the ADMA supported the diagnostic profile, showing an AUC of 0.85 with (sensitivity, 92.0\%; specificity, 91,9\%).

\section{Conclusion}

Assessment of serum ADMA in combination with other routine tests (LDH1, CKMB) and cardiac troponin $\mathrm{T}$ may give good prediction for early diagnosis of $\mathrm{MI}$ in patients with thalassemia.

\section{Competing interest}

The authors certify that there is no actual or potential conflict of interest in relation to this article.

\section{Acknowledgment}

This project was funded by the Deanship of Scientific Research (DSR) at King Abdulaziz University, Jeddah, under grant No (G-362-363-38). The authors, therefore, acknowledge with thanks DSR for technical and financial support.

\section{References}

1. "What Are the Signs and Symptoms of Thalassemias?". NHLBI. July 3, 2012.

2. Singer ST, Kuypers FA, Styles L, Vichinsky EP, Foote D, Rosenfeld H. Pulmonary hypertension in thalassemia: association with platelet activation and hypercoagulable state. Am J Hematol. 2006;81(9):670-675.

3. Palmer RM, Ferrige AG, Moncada S. Nitric oxide release accounts for the biological activity of endothelium-derived relaxing factor. Nature. 1987; 327:524-526.

4. Furchgott RF, Zawadzki JV. The obligatory role of endothelial cells in the relaxation of arterial smooth muscle by acetylcholine. Nature. 1980; 288:373-376.

5. Vallance P, Leone A, Calver A, Collier J, Moncada S. Accumulation of an endogenous inhibitor of nitric oxide synthesis in chronic renal failure. Lancet. 1992; 339:572575.

6. Leiper J, Nandi M, Torondel B, Murray-Rust J, Malaki M, O'Hara B, Rossiter S, Anthony S, Madhani M,Selwood D, SmithC, Wojciak-Stothard B, Rudiger A, Stidwill R, McDonald NQ, Vallance P. Disruption of methylarginine metabolism impairs vascular homeostasis. Nat Med. 2007; 13:198-203.

7. Hasegawa K, Wakino S, Tatematsu S, Yoshioka K, Homma K, Sugano N, Kimoto M, Hayashi K, Itoh H. Role of asymmetric dimethylarginine in vascular injury in transgenic mice overexpressing dimethylarginie dimethylaminohydrolase 2. Circ Res. 2007; 101:e2-e10.

8. Dayoub H, Achan V, Adimoolam S, Jacobi J, Stuehlinger MC, Wang BY, Tsao PS, Kimoto M, VallanceP, Patterson AJ, Cooke JP. Dimethylarginine dimethylaminohydrolase regulates nitric oxide synthesis: genetic and physiological evidence. Circulation. 2003; 108:3042-3047.

9. Chan JR, Böger RH, Bode-Böger SM, Tangphao O, Tsao PS, Blaschke TF, Cooke JP. Asymmetric dimethylarginine increases mononuclear cell adhesiveness in hy-

African Health Sciences Vol 18 Issue 3, September, 2018 
percholesterolemic humans. Arterioscler Thromb Vasc Biol. 2000; 20:1040-1046.

10. Hogg N, Kalyanaraman B, Joseph J, Struck A, Parthasarathy S. Inhibitionof low-density lipoprotein oxidation by nitric oxide. Potential role in atherogenesis. FEBS Lett. 1993; 334:170-174.

11. Jiang DJ, Jia SJ, Dai Z, Li YJ. Asymmetric dimethylarginine induces apoptosis via p38 MAPK/caspase-3-dependent signaling pathway in endothelial cells. J Mol Cell Cardiol. 2006; 40:529-539.

12. Willoughby SR, Rajendran S, Chan WP, Procter N, Leslie S, Liberts EA, Heresztyn T, Chirkov YY, Horowitz JD. Ramipril sensitizes platelets to nitric oxide: implications for therapy in high-risk patients. $\mathrm{IAm}$ Coll Cardiol. 2012; 60:887-894.

13. S. Nikolidakis, C. Flessa, N. Nikolaou, et al.Brain natriuretic peptide as marker of myocardial iron load in beta-thalassemia. Int J Cardiol, 118 (2007), pp. 408-409.

14. H. Isma'eel, A. Taher, W. Shamseddeen, et al. SAECG parameters and left ventricular chamber sizes: lesson from anemia conditions in thalassemia major patients. Int J Cardiol, 113 (2006), pp. e102-e104.

15. H Isma'eel, W Shamseddeen, A Taher, et al. Ventricular late potentials among thalassemia patients. Int J Cardiol, 132 (2009), pp. 453-455.

16. G Guz, A Sahinarslan, AW Dhondt, et al.Elevated cardiac troponin $\mathrm{T}$ in hemodialysis patients receiving more intravenous iron sucrose. Ren Fail, 26 (6) (Nov 2004), pp. 663-672.

17. Wang J, Pantopoulos K. Regulation of cellular iron metabolism. Biochem J. 2011;434(3):365-81. doi: 10.1042/ BJ20101825.

18. Wood JC. Impact of iron assessment by MRI. Hematology Am Soc Hematol Educ Program. 2011;2011:443-50. doi: 10.1182/asheducation-2011.1.443.

19. Kaplan S. Biochemical markers of myocardial injury in children. Circulation. 1997;96(8):2496-7.

20. Han Y, Liao X, Gao Z, Yang S, Chen C, Liu Y, Wang WE, Wu G, Chen X, Jose PA, Zhang Y, Zeng C.Clin c'TnI Exacerbates Myocardial Ischemia/Reperfusion Injury by Inducing Adhesion of Monocytes to VECs via TLR4/ NF- $x$ B-dependent Pathway. Sci (Lond). 2016 Sep 28. pii: CS20160373.

21. C.P. Cannon, C.H. McCabe, P.H. Stone et al., Circadian variation in the onset of unstable angina and non-Qwave acute myocardial infarction (the TIMI III Registry and TIMI IIIB), Am J Cardiol 79 (1997), 253-258.

African Health Sciences Vol 18 Issue 3, September, 2018
22. Cannon CP, McCabe CH, Stone PH, Schactman M, Thompson B, et al: Circadian variation in the onset of unstable angina and non-Q-wave acute myocardial infarction (The TIMI III registry and TIMIIIIB). Am J Cardiol, 1997;79:253-258

23. M.C. Cohen, K.M. Rohtla, C.E. Lavery et al.,Meta-analysis of the morning excess of acute myocardial infarction and sudden cardiac death, Am J Cardiol79 (1997), 1512-1516.

24. J.R. Leiza, J.M. de Llano, J.B. Messa et al., New insights into the circadian rhythm of acute myocardial infarction in subgroups, Chronobiol Int 24 (2007), 129-141.

25. J.R. Marler, T.R. Price, G.L. Clark et al., Morning increase in onset of ischemic stroke, Stroke 20 (1989), 473506.

26. J.E.Muller, P.H. Stone, Z.G. Turi et al., Circadian variation in the frequency of onset of acute myocardial infarction, N Engl, J Med 313 (1985), 1315-1322.

27. James EM, Peter HS, Zoltan GT, John DR, Charles AC, Corette P etal., (1985); Circadian Variation in the Frequency of Onset of Acute Myocardial Infarction. N Engl J Med, 313:1315-22.

28. M.W. Millar-Craig, C.N. Bishop et al., Circadian variation of blood-pressure, Lancet 1 (1978), 795-797.

29. A.M. Ehrly and G. Jung, Circadian rhythm of human blood viscosity, Biorheology 10 (1973), 577-583.

30. G.H. Tofler,D.Brezinski, A.I. Schafer et al., Concurrentmorning increase in platelet aggregability and the risk of myocardial infarction and sudden cardiac death, $N$ Engl J Med 316

31. Solomon B, HYPERLINK “javascript:void(0);” Magdi H, HYPERLINK “javascript:void(0);” Henrietta R, HYPERLINK “javascript:void(0);” Lori M, HYPERLINK “javascript:void(0);” Uri G (1993). HYPERLINK "https://www.amjmed.com/is sue/S0002-9343(00) X0602-X" Circadian variation and possible external triggers of onset of myocardial infarction: Volume 94, Issue 4, Pages 395-400 x

32. D.A. Brezinski, G.H. Tofler, J.E. Muller et al., Morning increase in platelet aggregability. Association with assumption of the upright posture, Circulation 78 (1988), 35-40.

33. M. Fujita and D. Franklin, Diurnal changes in coronary blood flow in conscious dogs, Circulation 76 (1987), 488-491.

34. J.E. Muller, G.H. Tofler, P.H. Stone. Circadian variation and triggers of onset of acute cardiovascular disease, Circulation 79 (1989), 733-743. 